\title{
Animal Organism Strain
}

National Cancer Institute

\section{Source}

National Cancer Institute. Animal Organism Strain. NCI Thesaurus. Code C94171.

A group of presumed common ancestry with clear-cut physiological but usually not morphological distinctions. 